NBER WORKING PAPER SERIES

\title{
ADJUSTMENT AND STRUCTURAL CHANGE \\ UNDER SUPPLY SHOCKS
}

Michael Bruno

Working Paper No. 814

\author{
NATIONAL BUREAU OF ECONOMIC RESEARCH \\ 1050 Massachusetts Avenue \\ Cambridge MA 02138 \\ December 1981
}

The research reported here is part of the NBER's research program in International Studies. Any opinions expressed are those of the author and not those of the National Bureau of Economic Research. 
NBER Working Paper \#814

December 1981

\section{ADJUSTMENT AND STRUCTURAL CHANGE UNDER SUPPLY SHOCKS}

\section{ABSTRACT}

The resource boom effect and the input price effect of raw material price changes are analyzed within a two-period, two-sector (plus resource industry), open economy framework. Diagrammatic exposition is used to study the 'dutch disease', and in particular the distinction between the short term wealth effects (causing a real appreciation and a movement of variable factors from tradable to non-tradable industries) and between the long-run effects on total investment, its sectoral allocation and its finance by foreign borrowing. The framework further enables analysis of the different allocational effects of temporary versus permanent raw material price increases, when the two sectors differ in material use. Also discussed are the effects of changes in the world interest rate on factor allocation and foreign borrowing as well as the allocational effects of government intervention in the case of temporary real wage rigidity.

Michael Bruno Department of Economics Hebrew University Jerusalem, Israel

Tel. (2) -636015 
UNDER SUPPLY SHOCKS

\section{Introduction*}

Macro-economic adjustment and long-term structural changes are often closely related, yet they are usually kept in separate analytical boxes. Nowhere is the inadequacy of such dichotomy more apparent than in the understanding of the developments and policy response of individual countries after the supply shocks of the 1970s. Raw materials price increases played a major role in the ensuing stagflation, which could be perceived as a short-term macro-economic adjustment problem. However, as time progressed it became more and more clear that the longer run implications of these shocks on productivity and profitability are at least as important.

There are two different aspects of raw material price effects which have been discussed under separate headings. One is the resource boom effect (see, for example, corden and Neary (1980)). If a country is a net exporter of a raw material whose price has increased, there will be a short run increase in the relative price of non-tradable goods (or a real appreciation) and a shift in variable factors out of existing tradable goods such as manufacturing, say, and into services. Relative profitability will further affect

* This paper is part of a project on Structural Adjustment in Open Economies conducted together with Jeffrey Sachs at the National Bureau for Economic Research in Cambridge, Mass. and at the Falk Institute for Economic Research, Jerusalem. Financial support by the National Science Foundation and the Ford Foundation is gratefully acknowledged.

I have benefitted from discussions with Jeffrey Sachs in the preparation of this paper. Likewise, I am indebted to Lars Svensson, Lars Calmfors, and other participants at the 1981 Saltsjobaden conference for helpful comments on an earlier draft. Svensson has independently worked out several of the propositions analyzed here (see Svensson (1981)). 
today's investment and therefore future production and capital in place in the various sectors. It is important to stress, however, that this is only one example of a pure wealth effect, which could also take place when an oil discovery is announced or, in a completely different context, when a country receives an unexpected foreign currency transfer (much like the old "transfer problem"). The analysis of this type of problem is best conceived in a framework in which international capital mobility is allowed for, because a wealth change will affect the country's borrowing.

Another, probably more important, aspect is that of the role of raw materials as a major input into the productive system. This may hit both net importers as well as net exporters of such material and would tend to shift resources away from a raw material intensive activity into less-intensive ones. This, too, might cause "deindustrialization" but for a different reason. In this context, it is important to make the distinction between temporary and permanent change in raw material prices. The former may have wealth effects but need not cause long-run changes in relative prices. It is mainly the latter that will affect investment behavior.

The present paper extends an earlier factor-price-frontier analysis of mine (1981) to a two-sector framework (sections I and II). It then analyzes the above issues in a two-period dynamic framework which is a stripped down version of a model that was previously used for simulation experiments (Sachs (1980), Bruno and Sachs (1981)). 1 $\bar{l}$ Louis Dicks-Mireaux is presently applying a similar framework for the U.K. 
After laying out the ingredients of the model in terms of production (II), household behaviour (III), investment and the current account (IV), diagrammatic exposition is used to show the effects of pure wealth and public expenditure changes (V), temporary and permanent change in raw material prices (VI) as well as the effect of changes in world interest rates and alternative current account objectives (VII). The paper ends with a brief discussion of the effect of short-term real wage rigidity and the related policy response.

\section{The factor-price-frontier, raw material prices and dynamic}

\section{adjustment}

The effect of raw material prices on the supply side of an open economy is best illustrated within the framework of the factor price frontier, in a three factor production world, which will here be reiterated only in summary form. Assume first that the economy consists of a single sector and let $Q=Q(L, K, N)$ be a well-behaved constant returns production function for gross output of a final good using labour, L, capital, K, and a raw material, N. The price of the output is $\mathrm{P}$, and that of the raw material is $\mathrm{P}_{\mathrm{n}}$. For the time being assume that the relative price $\Pi_{n}=P_{n} / P$ is given (as is the case if both $\mathrm{N}$ and $\mathrm{Q}$ are tradeable goods in a small open economy). Let $Y$ be the real income derived, $Y=Q-\Pi_{n} N$, and assume optimal use of $N$ such that $\partial Q / \partial N=\Pi_{n}$. Denote the real returns (marginal products) to labour and capital by $W_{p}$ and $R$ respectively.

The factor-price frontier (FFP) summarizes the information about the technology in terms of the maximal combinations of the three marginal factor products, $\phi\left(w_{p}, R, \Pi_{n}\right)=0$. The curve $\phi^{0}$ is drawn in 
$W_{P}$ - R space (see Figure 1) for a given relative raw-material price $\pi_{n}^{O}$ is downward sloping and convex to the origin. The slope of the tangent at the point $A$ measures the capital/labour ratio that corresponds to the pair of factor prices $\left(\mathrm{R}^{\circ}, \mathrm{W}_{\mathrm{p}}{ }^{\circ}\right)$ and its intercept on the $W_{\mathrm{p}}$ axis (OT) measures $\mathrm{Y} / \mathrm{L}$. Likewise the intercept on the $\mathrm{R}$ axis (OS) measures $Y / K$. The elasticity of FPF at the point $A=S A / T A$ measures the relative shares of capital and labour in $\mathrm{Y}$.

Weak separability of the production function which will be assumed here $\{Q=Q[V(L, K), N]\}$ implies weak separability of the dual FPF, i.e., $\phi$ will take the form $\phi\left[f\left(W_{p}, R\right), \Pi_{n}\right]=0$. A raw-material price increase, like Hicks-neutral technical regress, is represented by a homothetic inward shift of the FPF from $\phi^{O}$ to $\phi^{\prime}$. Only at the point $\mathrm{C}$ on the new FPF, on a ray OA, will the capital/ labour ratio be the same as at $A$. C is thus a full-employment point, in the short run (when $K=\bar{K}, L=\bar{L}$ ). Both real factor rewards at $C$ must fall at the same rate from their original level at A. Total real income per unit of labour (Y/L) likewise falls by the same proportion from OT to OM (and $\mathrm{Y} / \mathrm{K}$ from $\mathrm{OS}$ to $\mathrm{ON}$ ). The case of real wage rigidity at $W_{p}{ }^{\circ}$, which may occur in the very short run, is represented by the point $B$ where $R$ and $Y / K$ must of necessity fall by more than at $\mathrm{C}$ and the capital/ labour ratio is higher than at $\mathrm{C}$. At the initial/capital stock $\bar{K}, L$ must fall and unemployment will emerge, as long as the real wage does not fall by the required amount. ${ }^{1}$

In the putty-clay case in which the capital/labour ratio cannot immediately adjust to the new factor prices, the various solutions are given along the line FCG, i.e. in the rigid real wage, rigid capital/ labour ratio case the economy will be at $F$ and not at $B$, the rate of profit falling by more than at $B$, and $L$ staying constant.

One should also point out that under an alternative technological assumption the FPF need not shift homothetically. See Bruno (1981) for a more detailed discussion. 
Figure 1

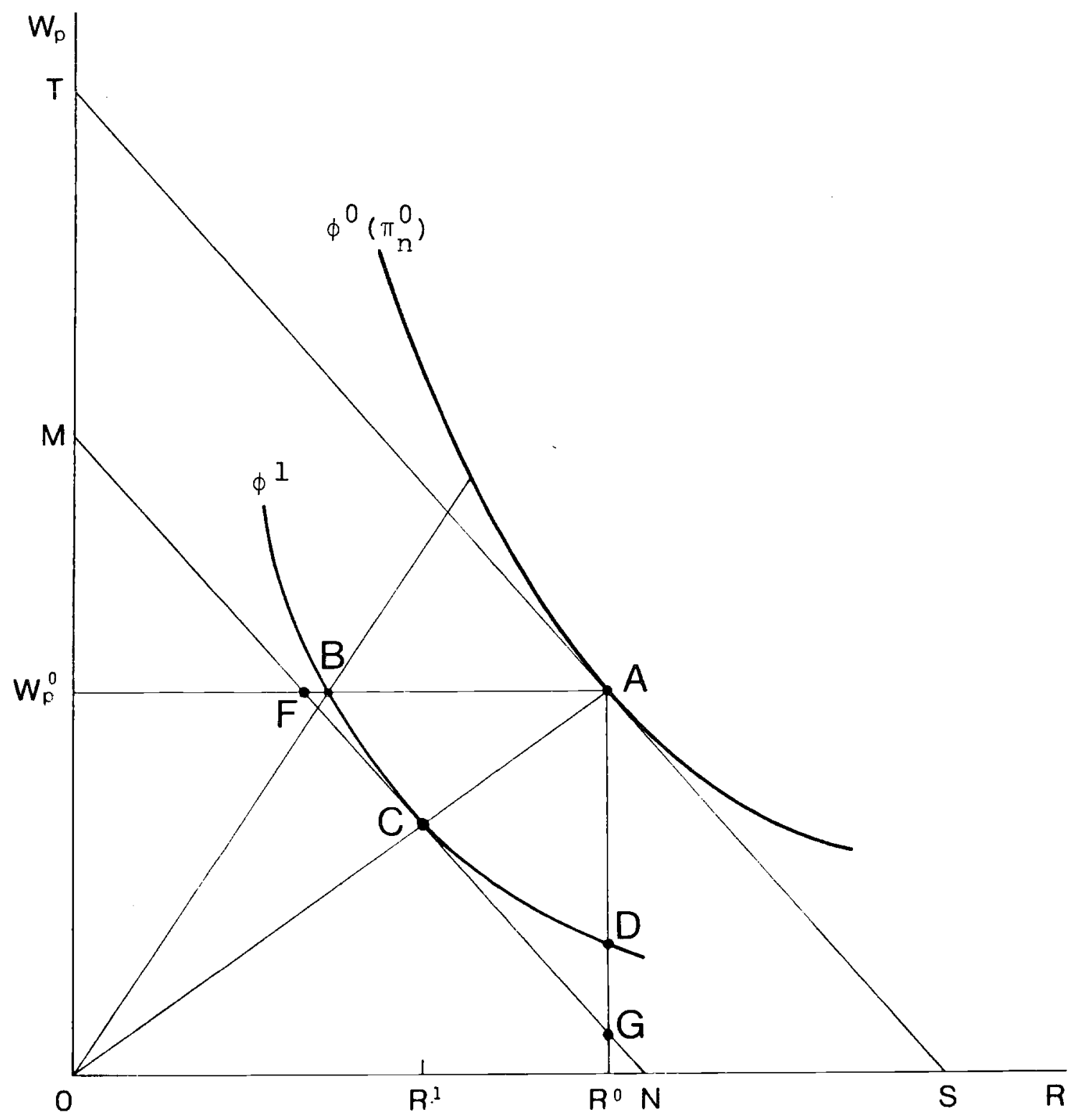


The polar case to the very short run $\left(\mathrm{w}_{\mathrm{p}}=\mathrm{w}_{\mathrm{p}}^{\mathrm{O}}\right)$ is that of an imposed long-run real rate of return $\left(R=R^{\circ}\right)$. This is represented by the point $D$, to be termed the long-run, at which the real wage and the capital/labour ratio are below their levels at $c$. In contrast to $C$, the point $D$ may represent an equilibrium steadystate level after capital has adjusted downward to a given real rate of return, $\mathrm{R}^{\circ}$. With full employment of labour, capital and output (gross and net) at D must both lower than at the initial point $A$.

To see the short-run and long-run implications of a permanent raw material price shock within this framework one may consider some simple dynamics in terms of two key variables, the real wage and the capital stock. The real wage can be made to change as a function of unemployment, in Phillips curve fashion. The capital stock can be made to adjust via an investment function that will depend in some measure on the instantaneous and future expected profit rate. With the aid of such a two-equation dynamic model, one can analyze the alternative paths leading to an ultimate steady state at the point $D^{1}$ An alternate procedure, which we shall adopt in the more detailed two-sector discussion below, is to think of the horizon as consisting of two periods,

$\bar{l}$ one has to keep in mind that a growing economy will usually also exhibit pure technical progress. To avoid the need to have the FPF simultaneously shift outward, when there is technical progress, one may instead redefine factor products to be measured in intensity units. Thus in the empirically relevant case of Harrod neutral (or labour augmenting) technical progess, for example, the real wage $\left(W_{p}\right)$ must be reinterpreted as being measured relative to its long run trend. Another implication of this is that when we talk of a fall in capital-labour ratios what may be implied is only a fall relative to what it would be in the absence of the exogenous shock. 
the short run, in which the capital stock is fixed, and the second period, the long run, for which first period investment may affect long-run capital in place. In this way today's investment is uniquely determined by the expected future rate of profit, which in turn depends on the assumptions made about future factor prices and the extent of international capital mobility.

II. A two-period model of production and factor allocation There are a number of interesting issue, relating to the role of raw materials, which are of necessity ignored when one looks at a single sector economy. ${ }^{l}$ Demand has so far played no role at all. Also there was no role for endogenous changes in relative commodity prices leading to compositional shifts within the economy. In the context of the role of raw materials compositional shifts be of great importance in more than one respect. A mineral boom leads to the so-called 'dutch disease', whereby an existing tradable goods industry may be squeezed out by real appreciation of the exchange rate, while a domestic service industry may expand (see Corden and Neary (1981), Neary and Purvis (1981) and van wijnbergen (1981)). A more direct effect of a rise in the price of raw materials might be to contract the industry that is relatively intensive in raw material use while a less raw material intensive industry might contract less or even expand. 2

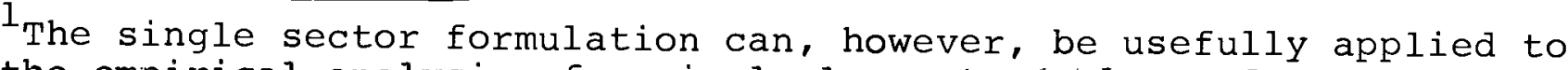
the empirical analysis of a single large tradable goods sector such as manufacturing.

2 If the country is a producer of both the raw material and the raw material using final tradable goods, such as most manufactures, deindustrialization may thus occur for a combination of both reasons, as is the case

in the U.K., for example.
} 
In the case of both phenomera it is important to distinguish between short-run and long-run effects of the exogenous changes that are taking place. In the short run only variable factors (e.g. labour) may be free to move from one sector into the other (If real wages are rigid there may also be room for government intervention). Relative profitability changes may, however, induce long-run changes in capital investment patterns. Whether the latter will in fact take place in turn depends on the extent to which the exogenous changes (e.g. in mineral prices) are perceived to be temporary or permanent. All of these considerations lead to the choice of a multisectoral as well as inter-temporal framework of analysis.

A natural extention of the model briefly discussed in the previous section would be one in which another non-tradeable goods sector is added on, in true Scandinavian tradition. Its extention to an infinite horizon framework becomes analytically intractable, as the number of state variables jumps to three or more. One way out is to run computer simulations of such models which can be made as complex as one wishes (see Sachs, (1980), Bruno and Sachs (1981)). Useful as these are, they do, however, have the drawback that it is often hard to see through how particular results depend on specific numerical assumptions made.

To obtain relative analytical simplicity we shall here sacrifice the full fledged long-term horizon. Much of what is relevant in the distinction between the short and the long-run can be seen from looking at two-period simplifications of the world. Even a rational expectations view of investment, based on future prices, can be 
expressed in this way, without need to bring in explicitly Tobin's $q$ or the 'costs of adjustment.' Finally the view of the balance of payments in its intertemporal allocation aspects can be fitted well into this scheme. ${ }^{1}$

Consider a two-commodity framework, tradeables (or the 'foreign' sector with subscript f) and domestic non-tradeables (with subscript d) within a two-period horizon (using superscript $t=1,2)$.

Production of tradeables $Q_{f}=Q_{f}\left(L_{f}, \bar{K}_{f}, N\right)$ uses inputs of labour $\left(L_{f}\right)$, fixed initial capital $\left(\bar{K}_{f}\right)$ and raw materials $(N)^{2}$. It supplies the demand for private consumer goods $\left(\mathrm{C}_{f}\right)$, investment goods (I) and net exports (X). The latter may be negative (net imports). The domestic price of tradeables $\left(\mathrm{p}_{\mathrm{d}}\right)$ equals the world price $\left(p^{*}\right)$ times the exchange rate (e). The non-tradeable goods sector will be assumed to use only labour and capital, $Q_{d}=Q_{d}\left(L_{d}, \bar{K}_{d}\right.$ ) and to supply only private $\left(C_{d}\right)$ and public $(G)$ consumer goods. The respective sector specialization in the production of exports, investment goods and public consumption and in the use of raw materials is not essential but clearly simplifies the analysis. There is a third sector in the economy, producing a fixed quantity of tradeable raw materials $\left(\mathrm{H}^{l}, \mathrm{H}^{2}\right)$, for which the fixed inputs will not be separately accounted.

The country may be a net

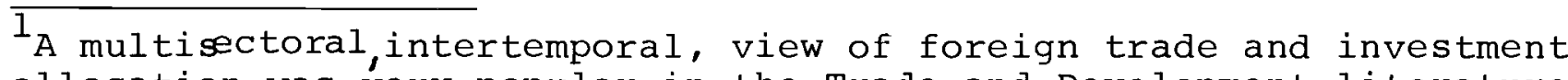
allocation was very popular in the Trade and Development literature of the 1960's, mostly based on empirical development proqramming models, but also including some theoretical contributions see e.g. Bardhan (1966), Bruno (1967). However, the associated short-term adjustment problem was usually discussed in a separate box. For recent two-period formulations of investment and the balance of payments see Razin (1980), Sachs (1981).

${ }^{2}$ We shall assume separability $Q_{f}=Q_{f}\left[V_{f}\left(L_{f}, K_{f}\right), N\right]$ as before, as well as constant returns. 
importer or net exporter of raw materials which command a given world price $\mathrm{p}_{\mathrm{n}}^{*}$.

While the total labour supply is fixed in both periods $\left(L_{d}^{t}+L_{f}^{t}=\bar{L}^{t}\right)$ capital in each sector in the second period is augmented or contracted by the amount of tradeable investment goods produced (or traded) for each sector in the first period $\left(\mathrm{K}_{\mathrm{d}}^{2}-\overline{\mathrm{K}}_{\mathrm{d}}+\mathrm{K}_{\mathrm{f}}^{2}-\overline{\mathrm{K}}_{\mathrm{f}}=\mathrm{I}^{1}\right)$. For simplicity we assume no depreciation but allow for negative $I^{1}$. No new investment goods have to be produced in the second period since this represents the 'Iong-run' with $\mathrm{K}_{\mathrm{d}}^{2}, \mathrm{~K}_{\mathrm{f}}^{2}$ staying on for posterity.

The main distinction between the two periods is that in the first, the short-run, capital is held fixed and is sectorspecific, while in the second, the long-run, it is malleable. On the production side this model has its antecedents in the work of Mayer (1974) and others. The earlier model is here extended to take into account investment and wealth as well as the role of raw materials.

Production and factor rewards are obtained from firm maximization of discounted cash flow. If the relative price of domestic over foreign goods is denoted by $\pi=p_{d} / p_{f}{ }^{1}$ that of raw materials by $\pi_{n}$, the real wage in foreign good units is $w_{f}$ and the own rate of interest on foreign goods is $r$, firms $\operatorname{maximize}\left(Q_{f}^{1}+\pi^{1} Q_{d}^{1}-w_{f}^{1} L^{1}-\pi_{n}^{1} N^{1}-I^{1}\right)+(1+r)-1\left(Q_{f}^{2}+\pi^{2} Q_{d}^{2}-w_{f}^{2} L^{2}-\pi_{n}^{2} N^{2}\right)$ subject to the labour and production constraints. The usual first order conditions are obtained for both periods:

\footnotetext{
$1_{\text {The reciprocal of }} \pi\left(\mathrm{p}_{\mathrm{f}} / \mathrm{p}_{\mathrm{d}}=\mathrm{e} \cdot \mathrm{p}^{*} / \mathrm{p}_{\mathrm{d}}\right)$ is often termed the
real exchange rate.
} 
$M P L=\pi{ }^{t} \partial Q_{d}^{t} / \partial L_{d}^{t}=\partial Q_{f}^{t} / \partial L_{f}^{t}=w_{f}^{t} ; \quad M P N=\partial Q_{f}^{t} / \partial N=\pi_{n}^{t} \cdot$

For capital in the second period we get:

$R=\pi^{2} \partial Q_{d}^{2} / \partial K_{d}^{2}=\partial Q_{f}^{2} / \partial K_{f}^{2}=1+r$

(First period equality of marginal products at the initial

point $\overline{\mathrm{K}}_{\mathrm{d}}, \overline{\mathrm{K}}_{\mathrm{f}}$ is assumed).

Equations (1) give the conventional static optimal

allocations of variable factors of production in each period.

They simply say that for profit maximization, factors that

are mobileshould in each period be allocated so as to equate the marginal products in both sectors, subject to proper accounting of relative output prices $(\pi)$.

Equation (2), on the other hand, represents the intertemporal arbitrage condition. It says that investment in the first period and its allocation to capital growth (or contraction) in each sector must be such that the marginal products of capital by the second period in each sector will be equal to the given foreign real interest factor $(R=1+r)$.

We are now ready to make use of these production equilibrium conditions in order to return to a factor-price frontier framework, this time looking at the FPF's of both sectors within the same diagram.

While the factor price frontier for the $f$ good is $\phi_{f}\left(w_{f}, R, \pi_{n}\right)=0$ (see curve $\phi_{f}^{O}$ in Figure 2), that of the d good can be represented in the same diagram if written in the form $\phi_{d}\left(w_{f} / \pi, R / \pi\right)=0$. The curve $\phi_{\mathrm{d}}^{\circ}$ in Figure 2 represents the FPF for the initial relative price $\pi^{0}$. It is here drawn under the assumption that $d$ are more capital-intensive than $f$ goods. An increase in the relative price $\pi$ 


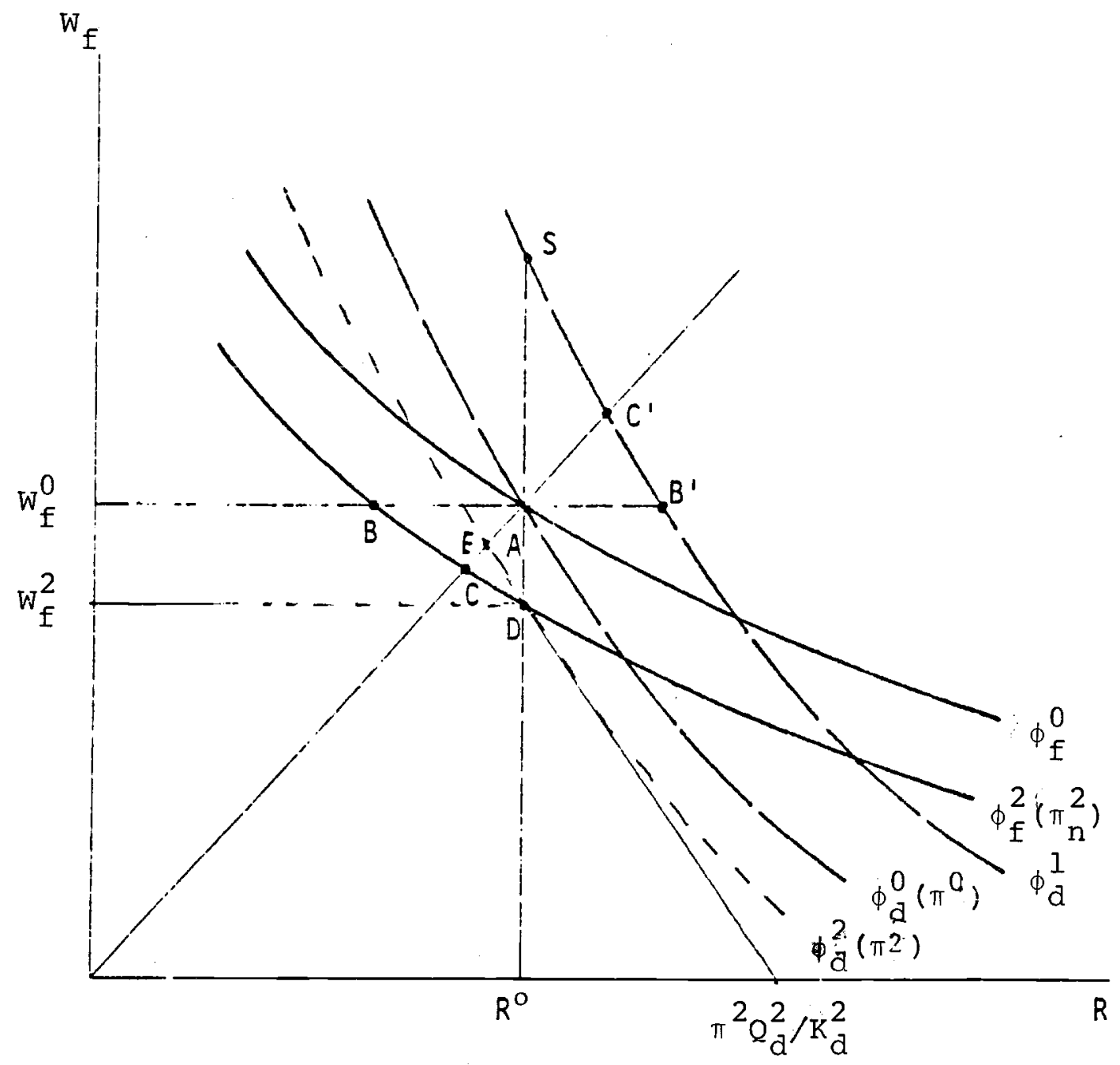

Figure 2 
(a real appreciation) will shift this curve homothetically outwards while a decrease in $\pi$ (a real depreciation) will shift it inwards.

Consider now the case in which the real rate of interest is given exogenously $R=R^{\circ}$, as would be the case under free international capital mobility ${ }^{l}$ and consider the case of a onceand-for-all increase in the relative price of raw materials, moving $\phi_{f}^{0}$ to $\phi_{f}^{2}$. The 'long-run' (i.e. second period) solution must entail a shift of $\phi_{d}^{0}$ to $\phi_{d}^{2}$ passing through the long-run point $D$. We can thus immediately deduce a number of important properties:

(1) The given marginal product of capital $\mathrm{R}^{0}\left(=1+r^{*}\right)$ fixes the long-run real wage $\mathrm{w}_{\mathrm{f}}^{2}$ as well as the relative price $\pi^{2}$ uniquely.

(2) We know that with an increase in raw material prices affecting only the $f$ sector $\pi^{2}$ must in this case fall in the second period i.e. $\pi^{2}<\pi^{0}$.

(3) From the geometry of Figure 2, we can deduce that the capital-labour ratio in the $d$ sector must fall (as it does in $f$ ) in the long-run. This follows from the fact that the tangent at $D$ has lower slope than at $E$, which in turn is the same as at $A$ (on $\phi_{d}^{O}$ ). We have thus established that a permanent rise in relative raw material prices, at given real rates of return to capital, must cause a long run fall in the real wage and in the capital intensities in both sectors as well as a real depreciation, on the assumption that the traded goods sector is the raw material intensive

\footnotetext{
We shall subsequently discuss the case in which $\mathrm{R}^{\circ}$ changes in the world market.
} 
industry. What is left open is the composition of output. Here demand must naturally play an important role.

III. Consumption, wealth and short-run equilibrium.

We shall assume that households decide on their consumption basket by maximizing discounted utility subject to a given net/ wealth constraint:

$$
C_{f}^{1}+\pi^{1} C_{d}^{1}+R^{-1}\left(C_{f}^{2}+\pi^{2} C_{d}^{2}\right)=\Omega
$$

Net household wealth $(\Omega)$ equals net discounted real $\mathrm{Y}_{\mathrm{f}}, \mathrm{Y}_{\mathrm{d}}$ in both sectors minus physical investment (I):

$$
\Omega=\left(\mathrm{Y}_{\mathrm{f}}^{1}+\pi^{1} \mathrm{Y}_{\mathrm{d}}^{1}\right)+\mathrm{R}^{-1}\left(\mathrm{Y}_{\mathrm{f}}^{2}+\pi^{2} \mathrm{Y}_{\mathrm{d}}^{2}\right)+\mathrm{H}-\mathrm{T}-\mathrm{I}^{1}
$$

where $Y_{f}^{t}=Q_{f}^{t}-\pi_{n}^{t} N^{t}, \quad Y_{d}^{t}=Q_{d}^{t}$ and $\mathrm{H}=\pi_{\mathrm{n}}^{1} \mathrm{H}^{1}+\mathrm{R}^{-1} \pi_{\mathrm{n}}^{2} \mathrm{H}^{2}=$ value of raw material resources $\mathrm{T}=\mathrm{T}^{1}+\mathrm{R}^{-1} \mathrm{~T}^{2}=\pi^{1} \mathrm{G}^{1}+\mathrm{R}^{-1} \pi^{2} \mathrm{G}^{2}=$ total cumulative government budget (in f units) and $\mathrm{T}^{\mathrm{t}}$ are taxes in both periods.

Making use of the fact that real incomes equal real factor products and that in the d-sector $C_{d}^{t}+G^{t}=Y_{d}^{t}=Q_{d}^{t}$, net wealth can be rewritten in the following simplified form:

$$
\Omega=\mathrm{Y}_{\mathrm{f}}^{1}\left(\pi^{1}, \pi_{\mathrm{n}}^{1}\right)+\pi^{1} \mathrm{C}_{\mathrm{d}}^{1}+\left[\mathrm{R}^{-1} \mathrm{~W}_{\mathrm{f}}^{2} \mathrm{~L}^{2}-\mathrm{R}^{-1} \pi^{2} \mathrm{G}^{2}+\overline{\mathrm{K}}_{\mathrm{d}}+\overline{\mathrm{K}}_{\mathrm{f}}+\mathrm{H}\right]
$$

Note that the expression in brackets in (4) is only a function of exogenous variables and does not involve first period investment which has been netted out (under firm optimal behavior). $\mathrm{Y}_{\mathrm{f}}^{1}$, on the other 
hand, can be expressed as a function of the relevant first period variables.

In the case of a flexible labour market, with which we shall deal most of the time, first period's net output of tradeables $\left(Y_{f}^{1}=Q_{f}^{1}-\pi_{n}^{1} N^{1}\right)$ can be written as a negative function of $\pi^{1}$, which equals the marginal rate of substitution on the short-run production possibility curve. It will also be a negative function of the exogenous $\pi_{n}^{1}$ (we ignore the fixed factors here). ${ }^{1}$ The next simplification is introduced by the choice of a linear logarithmic utility function for households (see Sachs (1981)), which implies that consumption of each good in each period is a fixed proportion of total net wealth:

$$
\beta C_{f}^{1}=\pi^{1} C_{d}^{1}=(1+\delta) R^{-1} \pi^{2} C_{d}^{2}=\beta(1+\delta) R^{-1} C_{f}^{2}=b \Omega
$$

where $\delta=$ pure discount rate and $\beta, b$ depend on the utility parameters. 2

Although this particular specification of the utility function is not required for most of the qualitative results to be obtained below, its very simple implications for consumption behavior enable a very convenient diagrammatic representation of the whole two period model and we therefore adopt it here.

${ }^{1}$ When real wages are slow to adjust (see below) the economy may not be on its PPC and we must instead use the supply function for $\mathrm{Y}_{\mathrm{f}}^{1}: \quad \mathrm{Y}_{\mathrm{f}}^{1}\left(\mathrm{w}_{\mathrm{f}}^{1}, \pi_{\mathrm{n}}^{1}\right)$. This will be smaller than $\mathrm{Y}_{\mathrm{f}}^{1}\left(\pi^{1}, \pi_{\mathrm{n}}^{1}\right)$.

${ }^{2}$ If the utility function is $U\left(C_{d}^{1}, C_{f}^{1}\right)+(1+\delta)^{-1} U\left(C_{d}^{2}, C_{f}^{2}\right)$ with $U\left(C_{d}, C_{f}\right)=\alpha \log C_{d}+(1-\alpha) \log C_{f}$ we have: $\beta=\alpha /(1-\alpha)$ and $\mathrm{b}=(2 i \delta)^{-1}(1+\delta) \alpha$. 
When we combine $\pi^{1} \mathrm{C}_{\mathrm{d}}^{1}=\mathrm{b} \Omega$ from (5) with the expression for net wealth (4), we can relate the present consumption of the domestic good $\left(\pi^{1} C_{d}^{l}\right.$, expressed in foreign good units) to its relative price and to the main exogenous variables determining the value of net wealth:

$$
\pi^{l} \mathrm{C}_{\mathrm{d}}^{1}=\mathrm{b} \Omega\left[\pi^{1} ; \pi_{\mathrm{n}}^{\mathrm{t}} \mathrm{H}^{\mathrm{t}}, \mathrm{R}, \mathrm{G}^{2}\right]
$$$$
\text { where } t=1,2
$$

The curved marked $b \Omega$ in the first quadrant of figure 3 gives a downward sloping demand curve for consumption of the domestic good. It will shift up or down depending on the exogenous increases or decreases in wealth. Private net wealth increases with the size of raw material deposits $\left(\mathrm{H}^{\mathrm{t}}\right)$ and falls with the rate of interest $(R)$ and the expected future government expenditure expenditure $\left(\mathrm{G}^{2}\right)$. The signs on the effect of raw material prices for each period depend on whether the economy is a net exporter or net importer of the raw material, i.e., on whether $\mathrm{H}^{\mathrm{t}}-\mathrm{N}^{\mathrm{t}} \geqslant 0 .{ }^{2}$ We shall make use of this property in analysing the effect of temporary or permanent increases in raw material prices.

All that we need to obtain the first period equilibrium is to add a supply schedule for domestic consumer goods:

$$
\mathrm{C}_{\mathrm{d}}^{\mathrm{l}}=\mathrm{Q}_{\mathrm{d}}^{\mathrm{l}\left(\pi^{1}\right)-\mathrm{G}^{1}}
$$

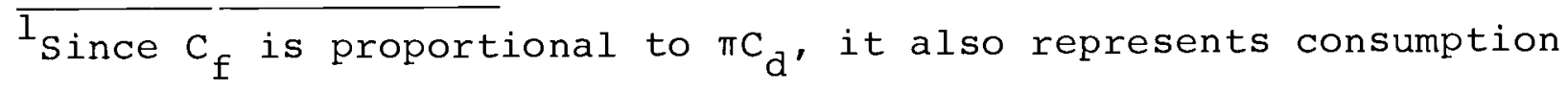
of the foreign good and total first period consumption. Note that $c_{d}$ in physical units is represented in this diagram by the slope of a ray from the origin. ${ }^{2}$ strictly speaking we have $\partial \gamma_{\partial} \pi_{n}^{1}=\mathrm{H}^{1}-\mathrm{N}^{1}, \partial \Omega / \partial \pi_{\mathrm{n}}^{2}=\mathrm{H}^{2}-\mathrm{N}^{2}$

- (positive term). The additional term in period 2 comes from the fiact that $R$ is held constant and not $\pi^{2}$. 
To conform to the variables in the diagram we multiply both sides of equation (7) by the relative price $\pi^{l}$. This curve is upward sloping and shifts down and to the right with increases in $\mathrm{G}^{l}$.

Even before looking at investment and second period equilibrium we can already deduce that any factor that increases wealth (in units of the $f$ good) will cause an increase in present consumption and will also cause a real appreciation in the short run. The latter in turn implies a shift of labor and production from tradeable goods to non-tradable goods e.g. from manufacturing into services. Here is one manifestation of de-industrialization in the short-run. Note that an increase in wealth may be caused by a variety of reasons, including the news that a North-Sea oil discovery is expected in the long-run (i.e. $\mathrm{H}^{2}$ rises). Likewise one gets the usual result that a temporary fiscal expansion ${\left(G^{1}\right.}^{1}$ rises but $G^{2}$ stays constant) crowds out private consumption and causes a real appreciation, if public expenditure is centered on domestic goods. More relevant in the present context, however, are the long-run effects of such expansion. We appropriately turn to investment and second period equilibrium. 
IV. Investment, foreign borrowing and long run production

Having shown how future factor prices and first period equilibrium are determined all that is left to complete the solution of the system is to show how the future composition of output and capital stock are determined. This will tell us what today's investment will be which in turn will determine the current account.

With constant returns to scale, output and labor demands can be written as proportions of capital stocks in each sector. Since future relative prices are uniquely determined we can write the second period supply equation for the domestic consumption good as a linear function of the capital stock:

$$
c_{d}^{2}=k_{d}^{2} g_{d}^{2}\left(w_{f}^{2} / \pi^{2}-G^{2}\right)
$$

where $g_{d}$ is output per unit of capital in the domestic goods industry. (Note that in figure 2 this is measured by the Rintercept of the tangent to the point D). Multiplying both sides of (8) by the second period relative price we can draw (8) as an upward sloping supply curve in the $\pi^{2} C_{d}^{2}$ and $K_{d}^{2}$ space (see quadrant II of figure 3). The use of the common vertical axis for the consumption good of both periods is justified by our simplifying assumption on consumption behavior (5), since the two are proportional to each other as long as the interest rates do not change $\left(\pi^{2} \mathrm{C}_{\mathrm{d}}^{2} / \pi{ }^{1} \mathrm{C}_{\mathrm{d}}^{1}=(1+\mathrm{r}) /(1+\delta)\right.$, by intertemporal optimality (5)). since consumption of the two periods are proportional, eq. and the curve marked $\left(Q_{d}^{2}-G^{2}\right)$ in figure 3 , uniquely determine the amount to be invested in the domestic industry $\left(\mathrm{K}_{\mathrm{d}}^{2}\right)$, as given, 
for example, at the point $\mathrm{A}_{2}$ *

The system is closed by assuming full employment and labor market clearing in the second period:

$$
\mathrm{k}_{\mathrm{d}}^{2} \lambda_{\mathrm{d}}^{2}\left(\mathrm{w}_{\mathrm{f}}^{2} / \pi^{2}\right)+\mathrm{k}_{\mathrm{f}}^{2} \lambda_{\mathrm{f}}^{2}\left(\mathrm{w}_{\mathrm{f}}^{2}, \pi_{\mathrm{n}}^{2}\right)=\overline{\mathrm{L}}^{2}
$$

Equation (9) is represented by the line marked $\bar{L}^{2}$ in quadrant III of figure 3 in which the two axes represent the two capital stocks, respectively. Its slope equals the ratio of capital/labor ratios $\left(\lambda_{d}^{2} / \lambda_{f}^{2}\right)$ in the two sectors. The way the line has been drawn here, relative to a $45^{\circ}$ line, assumes that the d sector is the more capital-intensive one. In the reverse capital intensity case, the $\bar{L}^{2}$ line must cut the $45^{\circ}$ line in the other direction. As we shall see relative intensities will matter as far as total investment requirements are concerned. The distance of the intercepts of the respective $45^{\circ}$ lines through the initial $\left(A_{3}\right)$ and any post-shock equilibrium (e.g. $B_{3}$ or $\left.D_{3}\right)$ will measure total investment requirements $I^{l}=\left(\mathrm{K}_{\mathrm{d}}^{2}+\mathrm{K}_{\mathrm{f}}^{2}\right)-\left(\overline{\mathrm{K}}_{\mathrm{d}}+\overline{\mathrm{K}}_{\mathrm{f}}\right)$.

Equations (6) - (9) and the corresponding four curves of figure 3 uniquely determine the equilibrium of the system in terms of the relevant endogenous variables. 1

Before we turn to the analysis of the response to various kinds of exogenous shocks, we must look at the implications for the current account.

When the first period labor market clears there will be a fifth equation to determine the first period real wage. 


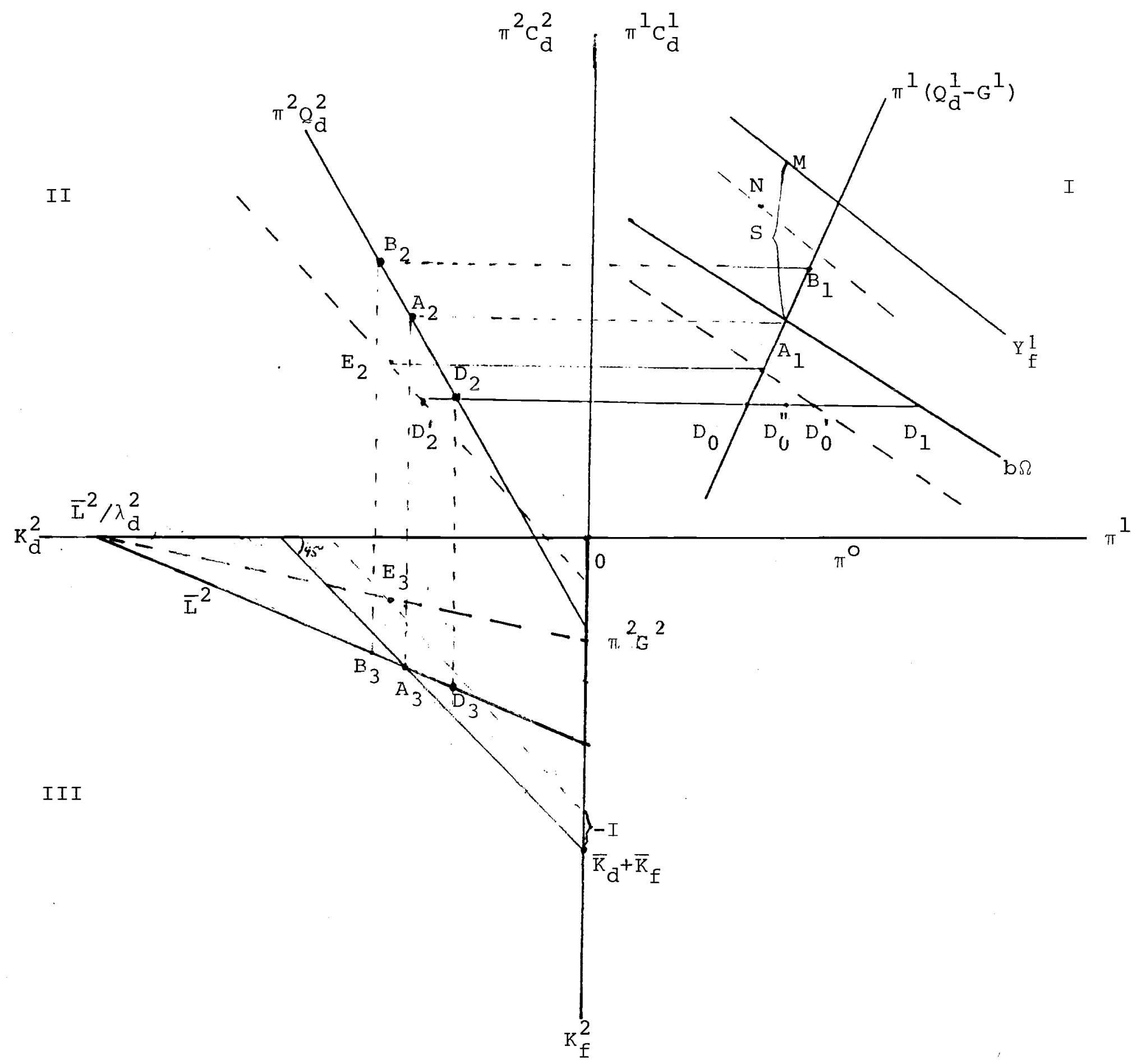

Figure 3 
The current account in $f$ units $\left(F^{t}\right)$ can be written down as follows $(t=1,2)$ :

$$
F^{t}=Q_{f}^{t}-\pi_{n}^{t}{ }_{n}^{t}+\pi_{n}^{t}{ }^{t}-C_{f}^{t}-I^{t}=Y_{f}^{t}+\pi_{n}^{t}{ }_{n}^{t}-C_{f}^{t}-I^{t}(10)
$$

where $I^{2}=0$ and $C_{f}^{2}=(I+\delta)^{-1}{ }_{R C}^{l}$ by $(3)$. Note that for each period $\left(\mathrm{Y}_{\mathrm{f}}+\pi_{\mathrm{n}} \mathrm{H}\right)$ is total net production of foreign exchange (including raw materials) while $\left(\mathrm{Y}_{f}+\pi_{\mathrm{I}} \mathrm{H}-\mathrm{C}_{\mathrm{f}}\right)$ must by definition be equal to total domestic savings $(S)^{1}$, which is $I+F . \quad T h e$ line marked $Y_{f}^{l}$ in quadrant $I$ of figure 3 describes $\beta\left[\mathrm{Y}_{\mathrm{f}}^{l}\left(\pi^{l}, \pi_{\mathrm{n}}^{l}\right)+\pi_{\mathrm{n}}^{1} \mathrm{H}_{\mathrm{n}}^{l}\right]$. Its vertical distance from the $?$ line (whose co-ordinate is $\pi^{1} C_{d}^{l}=\beta C_{f}^{l}$ ) is proportional to savings in the first period $\left(S^{l}\right)$. The $Y_{f}^{l}$ line is of necessity steeper than $\Omega$ so that ceteris paribus $\mathrm{s}^{l}$ falls with $\pi^{1}$. The difference $\left(S^{l}-I^{l}\right)$ measures the current account surplus $\left(F^{l}\right)$.

We shall consider two possibilities. One is the case in which there is no endogenous capital mobility and $F^{1}$ and $F^{2}$ are held equal to zero or to some pre-specified given numbers. The other case to which we shall turn first is the one in which borrowing and lending take place at a given world interest rate $r^{*}$. In this case we must have $R^{0}=\left(1+r^{*}\right)$ and the balance of payments constraint takes the form

$$
F^{1}+\left(1+r^{*}\right)^{-1} F^{2}=0
$$

'Another way of seeing this is to note that

$$
S=Y_{f}+\pi_{n} H+\pi Q_{d}-\left(\pi C_{d}+C_{f}\right)-\pi G=Y_{f}+\pi{ }_{n}^{H}-C_{f}
$$
since $Q_{d}=C_{d}+G$.

2 This vertical distance depends on $(\beta-b) Y_{f}^{l}\left(\pi^{l}\right)$ which is a negative function of $\pi^{1}$ since $\beta>b$. 
It is readily established that, upon substitution of (10), equations (11) and (3) become the same budget constraint for $\mathrm{R}=1+r^{*}$. In fact, the whole pattern of resource allocation and pricing described above could be got from the solution of an optimal growth problem in which society is assumed to maximize discounted utility, as above, subject to the various production and supply constraints in the two periods plus the intertemporal capital mobility condition (11).

V. The implications of pure wealth and expenditure effects

For the time being, we stick to the assumption that the longrun real interest rate is given and therefore once the future price of raw materials is set all future relative prices are known. Since investors are assumed to behave rationally and look only at future relative prices, factor proportions in each sector are known. Future intersectional allocation of capital, labour and output may still be affected by changes in wealth or in relative demand for different goods today. We first look again at pure wealth shifts and at changes in government expenditure.

Consider again the effect of an exogenous change in total wealth. A relevant example in the present context would be the discovery of North Sea oil (raising $H$ on the right-hand side of equation (6)). An alternative (not unheard of in my own country) would be a large foreign exchange transfer. In terms of figure 3 
this will show as an upward shift in the curve $\Omega$ in quadrant I with equilibrium taking place at points $B_{1}, B_{2}, B_{3}$, respectively, in the various quadrants. Consumption goes up (in all goods and periods), the relative price $\pi^{l}$ today rises, but only temporarily (note that second period's $\pi^{2}$ remains unchanged). This induces an increase in investment for non-tradables $\left(\mathrm{K}_{\mathrm{d}}^{2}\right)$ next period and a decrease in $\mathrm{k}_{f}^{2}$. Since capital-labour ratios are unchanged, this also implies a long-run movement of labour out of $f$ and into d, a clear manifestation of long-run de-industrialization (see the discussion of the "dutch disease", as, for example, in Corden and Neary $(1980))$.

As we have seen before this intersectoral movement of labour already starts in the first period as the relative price $\pi^{1}$ rises and capital is still frozen at its initial levels. One can use the FPF framework to show how FPF for d moves temporarily in an outward direction (see figure 2 move from $\phi_{d}^{0}$ to $\phi_{d}^{l}$ ). At the initial real wage $w_{f}^{0}$, the rate of return in the $d$ sector rises and $\overline{\mathrm{K}}_{\mathrm{d}} / \mathrm{L}_{\mathrm{d}}$ falls through the absorption of labour that is moving out of $d$ and into $f$. At the same time, $w_{f}$ will be rising to balance the labour market. Eventually $\pi$ falls back to the predetermined long-run level (which here is assumed to be the same as the initial relative price), and so does the real wage in both $f$ units $\left(w_{f}\right)$ and d units $\left(w_{f} / \pi\right)$, while the adjustment of capital stocks takes place. The production possibility curve will have a shift biased towards the 
$Q_{d}$ axis. Finally we note that in the case in which $\lambda_{d}^{2}<\lambda_{f^{\prime}}^{2}$ as is depicted in figure 3, total net investment in the first period will be positive (compare the $45^{\circ}$ lines through $A_{3}$ and $B_{3}$ ). It is easy to see that under reverse relative capital intensities, this intersectoral shift will take place together with a fall in total net investment.

There is an interesting point related to savings and current account behaviour which can be read off the diagram. Suppose the wealth shift comes only from the expectation of future oil finds (i.e., only $\mathrm{H}^{2}$ rises, while $\mathrm{H}^{1}$ does not change). In that case, the curve $\mathrm{Y}_{\mathrm{f}}$ stays put while $\Omega$ moves up. Savings today thus fall in expectation of greater riches (note the vertical distance between $B_{l}$ and $Y_{f}^{l}$ curve). If $I^{l}$ rises (in the case $\lambda_{d}^{2}<\lambda_{f}^{2}$ ) one can unambiguously associate these developments with a decrease in today's current account surplus (or increase in the deficit). 1

Consider again now an increase in government expenditure, which here is confined to d goods, coupled with an equivalent increase in taxes. As we have seen, this must crowd out private consumption expenditure. In figure 3 it will show in a downward shift of curve $Q \frac{l}{d}$ in quadrant 1 with $\Omega$ staying put and equilibrium now taking place at $D_{1}, D_{2}$, and $D_{3}$, respectively. Consumption falls, $\pi$ rises temporarily, $\mathrm{S}$ falls, $\mathrm{K}_{\mathrm{d}}^{2}$ falls and $\mathrm{k}_{\mathrm{f}}^{2}$ rises. Total investment falls if $d$ is more capital intensive than f. Total investment goes up - If one were to allow for investment in the H-industry, this point would be further strengthened. 
(and the current account falls) in the reverse capital intensity case. It is interesting to note that a d-biased increase in public consumption today in this case induces a shift into $f$ goods production tomorrow. This seemingly counter-intuitive result comes from the reduction in savings and the current account today. Production for net exports in the second period will thus have to increase(in the first period $Q_{f}^{l}$ falls with the temporary rise in $\pi^{1}$ ).

VI. Temporary or permanent increases in raw material prices ${ }^{1}$ Suppose now that $\pi_{n}^{1}$ goes up but $\pi_{n}^{2}$ is expected to stay put. This would be the case if a real oil price increase, say, is expected to be only temporary. The crucial question is what happens to net wealth. If the country is not self-sufficient today $\left(\mathrm{N}^{l}>\mathrm{H}^{l}\right)$, the $\Omega$ curve shifts down causing a fall in consumption, and in $\pi^{1}$, a fall in $K_{d}^{2}$ (as well as $L_{d}^{2}, Q_{d}^{2}$ ) and a rise in $K_{f}^{2}$ (as well as $L_{f}^{2}, Q_{f}^{2}$ ). Again this seemingly paradoxical result comes from the demand side, and it crucially depends on the assumed temporary nature of the raw material price increase.

Suppose now that both present and future prices of raw materials $\left(\pi_{n}^{1}, \pi_{n}^{2}\right)$ increase at the same rate. Again the $\Omega$ curve could shift up or down, depending on the effect on private wealth. If $I^{l}$ does not vary much, the analysis suggests a corresponding multi-period self-sufficiency condition. For a country that is

lFor a very similar analysis of raw material price shocks within a two-period model, as well as the welfare implications, see Svensson (1981). 
a net importer we would anyway expect a downward shift in the $\Omega$ curve. This time, however, the other curves in quadrant II and III shift as well. Consider first the supply curve $Q_{d}^{2}$. Since now the future relative price of $\left(\pi^{2}\right)$ also goes down, the intercept on the consumption axis $\left(-\pi^{2} G^{2}\right)$ is reduced. The slope of the $Q_{d}^{2}$ curve, on the other hand, depends on what happens to the output-capital ratio in the d sector (R-axis intercept of the tangent to $\phi \frac{2}{d}$ in figure 3 ). If, as is likely, it falls, the curve $\mathrm{Q}_{\mathrm{d}}^{2}$ rotates leftwards. In figure 3 , equilibrium is at the point $E_{2}$ which, relative to $A_{2}$, shows an increase in capital requirements in the d sector $\left(\mathrm{K}_{\mathrm{d}}^{2}\right)$. Similarly the curve $\overline{\mathrm{L}}^{2}$ in quadrant III now shifts inwards with equilibrium taking place at $E_{3} \cdot K_{f}^{2}$ thus falls while $\mathrm{K}_{\mathrm{d}}^{2}$ increases. In the case described in figure 3 total investment goes down. These results seem to agree generally quite well with the quantitative estimates obtained from a much more detailed empirical simulation model (Bruno and Sachs (1981)). However, one can see from inspection of the figure that there is a variety of possible outcomes depending on relative shifts in the constituent curves. (E.g., one could have both capital goods falling, if $\mathrm{Q}_{\mathrm{d}}^{2}$ rotates less to the left, or one could even conceive of an extreme case in which $\mathrm{K}_{\mathrm{f}}^{2}$ increases, though this seems relatively unlikely.)

To get a better idea of the various possible outcomes we consider the comparative statics of the model in more explicit 
analytical form. Let us denote the factor shares for labour and capital in the two sectors by $\alpha_{i}, \gamma_{i}(i=d, f)$ and that of raw materials in the TR sector by $\beta_{f}\left(\alpha_{d}+\gamma_{d}=\alpha_{f}+\beta_{f}+\gamma_{f}=1\right)$. The two factor price frontiers tell us that the rates of change (denoted by ${ }^{\wedge}$ ) of marginal factor products must obey the following equations:

$\begin{array}{ll}\text { TR: } & \alpha_{f} \hat{w}_{f}+\beta_{f} \hat{\pi}_{n}+\gamma_{f} \hat{R}=0 \\ \text { NT }: & \alpha_{d}\left(\hat{w}_{f}-\hat{\pi}\right)+\gamma_{d}(\hat{R}-\hat{\pi})=0\end{array}$

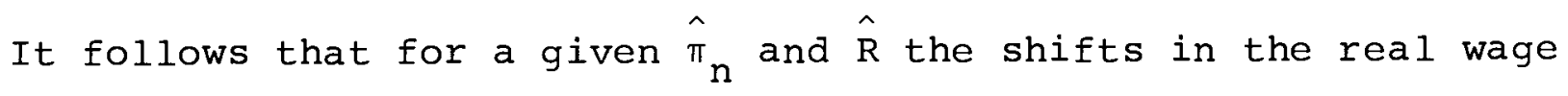
and the relative price of NT are uniquely determined as follows:

$$
\begin{aligned}
& \hat{w}_{f}=\alpha_{f}-1 \quad\left(\beta_{f} \hat{\pi}_{n}+\gamma_{f} \hat{R}\right) \\
& \hat{\pi}=\alpha_{d^{w}} \hat{w}_{f}+\gamma_{d} \hat{R}=-\alpha_{f}{ }^{-1} \alpha_{d} \hat{\beta}_{f} \hat{\pi}_{n}+\gamma_{d}\left(1-\gamma_{d}{ }^{-1} \alpha_{f}-\alpha_{\alpha_{d}}\right) \hat{R}
\end{aligned}
$$

For the special case $\hat{R}=0$, with which we have dealt so far, equation (15) gives an exact measure of the long-run reduction in the price of non-tradables for a "small" increase in $\pi_{n}$. When $R$ also changes (see discussion below) the second term in (15) shows that a long-run fall in $\mathrm{R}$ will lead to a further fall in the relative price $(\pi)$ if $d$ is more capital intensive than $f$, as is here assumed. (For the reverse capital intensity case a fall in $R$ would mitigate the long-run fall in $\pi$. ) 
Consider the production side now. Denoting the elasticities of substitution between labour and capital by $\sigma_{i}(i=d, f)$ we have:

$$
\hat{K}_{i}-\hat{i}_{i}=\sigma_{i}\left(\hat{w}_{f}-\hat{R}\right)
$$

For the d sector we thus find (substituting from (16) and assuming $\hat{R}=0$ )

$$
\begin{aligned}
& \hat{Q}_{d}-\hat{L}_{d}=\left(1-\alpha_{d}\right)\left(\hat{K}_{d}-\hat{L}_{d}\right)=-\alpha_{f}-1\left(1-\alpha_{f}\right) \alpha_{d} \beta_{f} \hat{\pi}_{n} \\
& \hat{Q}_{d}-\hat{K}_{d}=-\alpha_{d}\left(\hat{K}_{d}-\hat{I}_{d}\right)=\alpha_{f}-1 \alpha_{d} \sigma_{d} \beta_{f} \hat{\pi}_{n}
\end{aligned}
$$

and,

$$
\left(\hat{\pi}_{d}\right)=\hat{\pi}+\hat{Q}_{d}-\hat{K}_{d}=-\alpha_{f}-1 \alpha_{d} \beta_{f}\left(1-\sigma_{d}\right) \hat{\pi}_{n}
$$

Equation (17) thus shows that the output-capital ratio must fall, and likewise the slope of the $Q_{d}^{2}$ line in figure 3 , as long as the elasticity of substitution between labour and capital in d is less than 1 . It is interesting to note that in the special Cobb-Douglas case $(\sigma=1)$ it will stay put. We have thus justified the analysis of the change in quadrant II of figure 3. What can we explicitly say about the changes in the capital stocks (quadrant III, figure 3) as a result of an increase in raw material prices? Returning to the notation for period 2 we have, using equations (8) and (16): 


$$
\hat{\mathrm{K}}_{\mathrm{d}}^{2}=\hat{\mathrm{Q}}_{\mathrm{d}}^{2}-\left(\hat{\mathrm{Q}}_{\mathrm{d}}^{2}-\hat{\mathrm{K}}_{\mathrm{d}}^{2}\right)=\mathrm{c}\left(\hat{\mathrm{C}}_{\mathrm{f}}^{2}-\hat{\pi}^{2}\right)-\alpha_{\mathrm{f}}{ }^{-1} \alpha_{\mathrm{d}}{ }^{\sigma} \mathrm{d}_{\mathrm{f}} \hat{\pi}_{\mathrm{n}}^{2}
$$

where $\mathrm{c}=\mathrm{C}_{\mathrm{d}}^{2} / \mathrm{Q}_{\mathrm{d}}^{2}$.

Next we can substitute for $\hat{\pi}^{2}$ from equation (16) and write $\hat{C}_{f}^{2}=\theta \hat{\pi}_{n}^{2}$ where $\theta$ is the elasticity of total wealth with respect to a permanent raw material price change $\left(\pi_{n}^{1}=\pi_{n}^{2}\right)$.

We can thus write:

$$
\hat{\mathrm{k}} 2=\left[\alpha_{\mathrm{f}}{ }^{-1} \alpha_{\mathrm{d}} \beta_{\mathrm{f}}\left(\mathrm{c}-\sigma_{\mathrm{d}}\right)+\mathrm{c} \theta\right] \hat{\pi}_{\mathrm{n}}
$$

Likewise, we have

$$
\hat{\mathrm{L}}_{\mathrm{d}}^{2}=\hat{\mathrm{K}}_{\mathrm{d}}^{2}-\left(\hat{\mathrm{K}}_{\mathrm{d}}^{2}-\hat{\mathrm{L}}_{\mathrm{d}}^{2}\right) \text { which (using equations (16), (14) and }
$$

gives

$$
\begin{aligned}
\hat{L}_{d}^{2} & =\hat{K}_{d}^{2}+\left(\alpha_{d} \beta_{f} / \alpha_{f}\right) \hat{\pi}_{n} \\
& =\left[\alpha_{f}-1 \beta_{f} \sigma_{d}\left(1-\alpha_{d}\right)+c\left(\alpha_{f}^{-1} \alpha_{d} \beta_{f}+\theta\right)\right] \hat{\pi}_{n}
\end{aligned}
$$

Looking at signs and orders of magnitude of parameters there is a strong presumption that $\hat{\mathrm{L}}_{\mathrm{d}}^{2}>0$ and $\hat{\mathrm{Q}}_{\mathrm{d}}^{2}>0$ while $\hat{\mathrm{K}}_{\mathrm{d}}^{2}$ may be positive but need not necessarily be so. The ambiguity arises

I $\theta$ can roughly be approximated by the ratio to wealth $q^{f}$ the total self-sufficiency measure : $\left[\mathrm{H}^{\mathrm{I}}-\mathrm{N}^{1}+(1+\mathrm{r}) \mathrm{I}^{-1}\left(\mathrm{H}^{2}-\mathrm{N}^{2}\right)\right] / \Omega$. 
from the fact that $\theta$ is negative for a net importer while in (18) $\left(c-\sigma_{d}\right)$ may or may not be positive. ${ }^{1}$ If $I_{d}^{2}$ rises, then by construction $L_{f}^{2}$ must fall, and since $K_{f}^{2} / L_{f}^{2}$ is known to fall in response to a $\pi_{n}$ increase, $K_{f}^{2}$ must be falling and so do $Q_{f}^{2}$ and $\mathrm{Y}_{\mathrm{f}}^{2}$

We can thus state as an upshot that there is a strong presumption that employment, output and capital in the $f$ industry will fall and that employment and output (and maybe capital) in the $d$ industry will rise.

It is important to stress again that when it comes to drawing any lessons for reality everything that has been said here about sectoral changes should be interpreted as deviations from what long-run trend would otherwise be, and not necessarily as indicating absolute positive or negative levels of investments, etc. We have assumed zero population growth, no technical progress and no depreciation of capital. While relaxation of these assumptions would not pose particular difficulties, they do simplify the analysis, but at the same time require that one interpret the results with suitable modification.

VII. World equilibrium, changes in the rate of interest and the current account

So far we have conducted the analysis under the assumption Numerical example ( with reasonable orders of magnitude) : $\alpha_{\mathrm{d}}=0.6, \alpha_{\mathrm{f}}=0.4, \beta_{\mathrm{f}}=0.4, \sigma_{\mathrm{d}}=0.7, \mathrm{c}=0.8, \theta=-0.05$. We get (per 1 \% of $\hat{\pi}_{\mathrm{n}}$ ): $\hat{\mathrm{K}}_{\mathrm{d}_{2}}^{2}=0.02, \hat{\mathrm{L}}_{\mathrm{d}_{2}}^{2}=0.72, \hat{\mathrm{Q}}_{\mathrm{d}}^{2}=0.44$ (percent). If $\theta=-0.10, \hat{\mathrm{K}}_{\mathrm{d}}^{2}=-0.02, \hat{\mathrm{L}}_{\mathrm{d}}^{2}=0.68, \hat{\mathrm{Q}}_{\mathrm{d}}^{2}=0.40$ (percent). In both cases, $\hat{\pi}^{1}=-0.7, \hat{w}_{f}^{2}=-1.0$. 
that the world rate $r *$ remains constant. This is a very convenient device since it appropriately fixes the long-run factor prices and factor proportions. This particular small economy assumption need, of course, not hold if one thinks of the implications of an increase in raw material prices hitting all industrial countries at the same time. In the short and medium run, as experience has also shown, a shift in the world savings schedule and an investment short-fall may drive the real rate down, although it is not clear why this should be sustained for a very long period. I In any case, one may consider the implication of an exogenous change for a single country within the above model. Specifically let us consider a drop in $r^{*}$ on top of a permanent increase in $\pi_{\mathrm{n}}$.

A fall in $r *$ causes a rise in $w_{f}^{2}$ (or rather mitigates the fall in $w_{f}^{2}$ ). If $d$ is more capital intensive than $f$, there will be a further fall in $\pi^{2}$. The same analysis also shows that $Q_{d}^{2} / K_{d}^{2}$ as well as $\pi_{\mathrm{d}}^{2} / \mathrm{K}_{\mathrm{d}}^{2}$ fall relatively to their previous long-run solution. The fall in $r$ raises the present value of wealth $(\Omega)$, and thus shifts up the curve $\Omega$ in figure 3 , leading to a relative increase in consumption, $\pi^{I}$ and $Q_{d}^{1}$, and a relative fall in $Q_{f}^{1}$. Since the curve $\mathrm{Y}_{\mathrm{f}}^{1}$ stays the same, savings $\left(\mathrm{S}^{\mathrm{I}}\right)$ must fall in the process, as one would expect.

This will hold as long as the weighted marginal propensity to save out of wealth of the net exporters of raw materials outweighs the MPS for the net importers. 
The outcome in the second period depends on what happens to consumption demand for non-tradables which in turn is proportional to $(1+r) c_{f}^{2}$. The latter may go down since in all probability $\Omega$ (and thus $C_{f}^{2}$ ) increases by less than $(1+r)$ falls. So the question is whether the resulting relative fall in demand for $Q_{d}^{2}$ can outweigh the effect of rising per unit capital requirements. The term multiplying $\hat{\mathrm{R}}$ in a modified expression for $\hat{\mathrm{K}}_{\mathrm{d}}^{2}$ (as in (18)) turns out to be ambiguous in sign. ${ }^{1}$ Again the presumption is that it will certainly reduce $L_{d}^{2}$. Here the elasticity with respect to $R$ is

$$
\left(\left[\sigma_{d}\left(1-\alpha_{d}\right)\left(1-\beta_{f}\right) / \alpha_{f}\right]+c\left[1-\gamma_{d}+\alpha_{f}^{-1} \alpha_{d} \gamma_{f}\right]\right)
$$

which is always positive. If the fall in the rate of interest reduces $\mathrm{L}_{d}^{2}$ it certainly increases $\mathrm{L}_{\mathrm{f}}^{2}$. With the relative increase in $\mathrm{K}_{\mathrm{f}}^{2} / \mathrm{L}_{\mathrm{f}}^{2}$ the capital stock as well as the output of $\mathrm{f}$ in the second period must be higher than otherwise. With the fall in $C_{f}^{2}=(1+r) C_{f}^{1}$, it turns out that the current account in the second period $\left(F^{2}\right)$ must improve and therefore $F^{1}$ in the first period must worsen. 2

The final upshot, which makes intuitive sense, is that an exogenous fall in the interest rate makes for more net foreign

$\bar{l}$ For the numerical example given earlier this equals +0.3 , a fall in $R$ reduces $K_{d}^{2}$.

2 This would immediately follow if total investment ( ${ }^{l}$ ) rises; savings $\left(S^{1}\right)$, as we have seen, certainly falls. The rise in investments is probable but not certain while the fall in the difference $\left(F^{I}=S^{1}-I^{1}\right)$ is ambiguous. 
borrowing (or reduction in capital outflow) today at the expense of the future and this has a counterpart in the structure of production and consumption. Less production and more consumption (by imports) of tradables today and more production (less consumption) next period. Correspondingly the relative price $\pi$ falls less today (a smaller real depreciation) and more tomorrow. 1 This monotonic relationship between $r$ and the current account can also be used to consider the case in which we do not assume free capital mobility. Suppose the government sets a target for the current account which involves a smaller deficit (or larger surplus) than would be obtained as an endogenous solution of the system. 2 This implies government intervention in the form of fiscal and real exchange rate policy such as implicitly involves an increase in the domestic real rate of interest. The implications for the structure of production and consumption in both periods will be exactly the reverse of that found in the case previously considered. In other words, there will now be an increase in savings and in net production of $f$ today at the expense of less of the same tomorrow, with all the concomitant effects on patterns of investment and labour use.

The converse may also take place. A government may decide to run a larger deficit than would otherwise be obtained for reasons of supporting price stability or full employment. These

1 Again this is not unfamiliar from the trade and development literature (op. cit.).

2 We implicitly assume that only the government now conducts the foreign borrowing or lending with the budget absorbing the difference in interest rates. 
questions will be briefly discussed in the next section.

VIII. Real wage rigidity and other modifications

So far we have assumed wage and price flexibility and

automatic clearing of all markets. Under a raw material price shock unemployment may arise when real wages are temporarily downward rigid (see Bruno and Sachs, 1979). For simplicity consider such rigidity in terms of this period's wage in $\bar{f}$ units $\left(w_{f}\right) .^{1}$ In the extreme case in which $w_{f}$ is held fixed at its initial level $\left(w_{f}=w_{f}^{O}\right.$ in the "very short-run") a raw material price increase will now show in a greater reduction in real wealth since net output of $f\left(Y_{f}^{2}\right)$, for a given $w_{f}$, falls by more than it would fall otherwise. ${ }^{2}$ Wealth $(\Omega)$ will no longer aepend directly on $\pi$, and the $\Omega$ curve in figure 3 (quadrant I) will now be replaced by a line parallel to the $\pi$ axis which shifts down as $\pi_{n}$ increases, to a position like the line passing through points $D_{0}$ and $D_{1}$ in the figure. If $\pi$ were also downward rigid (say the nominal exchange rate were fixed and prices of $d$ $\left(p_{d}\right)$ are downward rigid), the economy would momentarily stay at the point $D_{0}^{\prime \prime}$, where there is excess supply in the commodity market (the demand for $\mathrm{C}_{\mathrm{d}}^{1}$ is less than $\mathrm{Q}_{\mathrm{d}}^{1}-\mathrm{G}^{1}$ ), as well as unemployment. If commodity prices are free to adjust, $\pi^{1}$ will fall and $C^{l}$ will rise to the point $D_{0}$, where the $d$ market clears 1 More realistically the consumption wage should be expressed in terms of an average of $w_{f}$ and $w_{f} / \pi$. Real wage rigidity may thus imply a constraint on the relationship between $w_{f}$ and $\pi$, rather than on $w_{f}$ alone.

2 Formally, this can be seen by showing that $\partial Y_{f} / \partial \pi_{n} \mid \overline{\bar{\pi}}-N$ while $\left(\partial \mathrm{Y}_{\mathrm{f}} /\left.\partial \pi h_{\mathrm{W}_{\mathrm{f}}}\right|^{=}-\mathrm{N}-\right.$ (positive term) 
clears but labour does not. Full employment could be reached, with a rigid real wage, at the point $D_{0}^{\prime}$. This corresponds to the case in which government expenditure is increased to insure full employment (the line $\Omega_{d}^{2}$ shifts to pass exactly through $D_{0}^{\prime}$ ), while taxes are suitably adjusted and domestic consumption of d falls.

Since consumption along with private wealth must be lower than in the flexible wage case (which corresponds to the points $E_{1}$ ' $E_{2}$, etc.), the effect in the second period is to reduce $K_{d}^{2}, L_{d}^{2}$ and $\mathrm{Q}_{\mathrm{d}}^{2}$ (point $\mathrm{D}_{2}^{\prime}$ in quadrant $\mathrm{II}$ ) and increase $\mathrm{K}_{\mathrm{f}}^{2}, \mathrm{~L}_{\mathrm{f}}^{2}$ and $\mathrm{Q}_{\mathrm{f}}^{2}$ relative to what they would otherwise be. This solution correspondingly implies that there will be a larger surplus (or smaller deficit) in the current account in the second period at the expense of the first period in which both domestic savings and the current account must fall.

The above analysis may look somewhat mechanistic since we have fixed the real wage independently of the state of the labour market in which case the size of public expenditure does not seem to have any quantitative effects in the future. This could easily be modified by assuming, in Phillips curve fashion, that $\mathrm{w}_{\mathrm{f}}$ changes smoothly as a negative function of the unemployment rate. In this case this period's changes in G will directly affect the size of the structural changes in the second period. ${ }^{1}$

I Note that we have assumed that the increase in $G^{1}$ is financed by increased taxes. Had we assumed instegd that this is financed by a decrease in next period's $\mathrm{G}^{2}$ (i.e., by debt) the intertemporal link would also show directly (by an upward shift in the $Q_{d}^{2}$ line in quadrant II of figure 3 ). 
As long as nominal money has not been incorporated in the model one cannot explicitly analyze inflation and the role of monetary policy. While this can be remedied formally by introducing money demand/supply and a nominal interest rate, the likely role of money can be guessed even without its explicit introduction. Money may have a real long-term effect in this model if there is short-term non-neutrality. As in similar models, some nominal price $\left(p_{d}, p_{f}\right.$ or $\left.w\right)$ must be temporarily rigid, in which case real private wealth (as well as $\pi$ and $w_{f}$ ) may change as a result of monetary policy, thus affecting next period's factor allocations in a way similar to that analyzed before.

We conclude our discussion by noting again that, with one exception, we have so far stuck to the simplification that only second period's quantities are affected by today's disturbances while relative prices were assumed to remain invariant. A more general approach should also allow for induced changes in long-run relative prices. We briefly mention one example where this may occur. Suppose we relax the assumption that the $f$ good is a perfect substitute for the world final good and assume instead that the individual country faces a downward sloping demand curve for its product (priced $p_{f}$ ) which is an imperfect substitute for the world final good (whose domestic price is $e \cdot p^{*} \neq p_{f}$ ). In that case the final goods terms of trade $\left(p_{f} / e p^{*}\right)$ become an 
additional endogenous relative price, which may now move the final position of the FPF for $f$ (the curve $\phi_{f}^{2}$ in figure 2), since the relative price of the raw material will also become endogenous ${ }^{1}\left[\pi_{n}=e{ }^{*}{ }_{n} / p_{f}=\left(p_{n} * / p *\right)\left(e p * / p_{f}\right)\right]$. What this implies is that present period's stabilization policies may affect next period's $\Pi^{2}$ and $w_{f}^{2}$ even though $r *$ is given. Once we introduce these and additional complications, however, there remains less advantage in considering an analytical model over simulations with a more realistically complex empirical framework. After all we set out with the objective of showing that considerable insight into some of the issues can be gained by looking at a stripped-down version of such a model.

1 Such argument, for a medium term context, explains why in face of the same external price shock (in terms of $\mathrm{p}^{*} / \mathrm{p}^{*}$ ) a country like Germany suffered a smaller internal increase in $\pi$ in the 1970s, compared to Japan or the U.K. (The implications for the differential productivity performance in manufacturing are discussed in Bruno, 1981.) 
References

Bardhan, P., "Optimal Foreign Borrowing," in K. Shell (ed.), Essays in the Theory of Optimal Growth, The MIT Press, 1966.

Berndt, E.R., and D.O. Wood, "Engineering and Econometric Interpretation of Energy-Capital Complementarity," American Economic Review, June, 1979.

Bruno, M., "Optimal Patterns of Trade and Development," The Review of Economics and Statistics, November 1967.

"Raw Materials, Profits and the Productivity slowdown," Discussion Paper No. 812, Falk Institute, Jerusalem, April 1981. (Also appeared as NBER Working Paper No. 660).

Bruno, M., and J. Sachs, "Supply versus Demand Approaches to the Problem of Stagflation," NBER Working Paper No. 382, August 1979. (Appeared in Macroeconomic Policies for Growth and stability, Institut fur Weltwirtschaft, Kiel, 1981.)

"Input Prices Shocks and the Slowdown in Economic Growth: Estimates for U.K. Manufacturing," presented at the Conference on Unemployment, Newnham College, Cambridge, July 1981.

Corden, W.M., and J.P. Neary, "Booming Sector and de-Industrialization in a Small Open Economy," mimeo, 1980.

Mayer, W., "Short-Run and Long-Run Equilibrium for a Small Open Economy," Journal of Political Economy, September/October 1974 .

Neary, J.P., and D.D. Purvis, "Sectoral Shocks in a Dependent Economy: Short-Run Accomodation and Long-Run Adjustment," mimeo, 1981.

Razin, A., "Capital Movements, Intersectoral Resource Shifts, and the Trade Balance," Seminar Paper No. 159, Institute for International Economic Studies, University of Stockholm, October 1980.

Sachs, J., "Energy and Growth under Flexible Exchange Rates," NBER Working Paper No. 582, November 1980; also forthcoming in Bhandari and Putnam (eds.), The International Transmission 
of Economic Disturbances under Flexible Exchange Rates, forthcoming, MIT Press, 1982.

, "Aspects of the Current Account Behavior of OECD Economies," presented at the Vth International Conference of the University of Paris-Dauphine on Money and International Monetary Problems, June 1981 .

Svensson, L.E.O., "Oil Prices and a Small Oil-Importing Economy's Welfare and Trade Balance: An Intertemporal Approach," Institute for International Economic Studies, University of Stockholm, October 1981.

van Wijnbergen, S., "Optimal Investment and Exchange Rate Management in Oil Exporting Countries: A Normative Analysis of the Dutch Disease," mimeo, Development Research Center, World Bank, Washington, 1981 . 